\title{
Silica matrix doped with calcium and phosphate by sol-gel
}

\author{
Lucimara C. Bandeira, Katia J. Ciuffi, Paulo S. Calefi, Eduardo J. Nassar*
}

Universidade de Franca, Av. Dr. Armando Salles Oliveira 201 Pq. Universitário, Franca, Brazil.

Email: ejnassar@unifran.br

Received 21 April 2010; revised 7 May 2010; accepted 10 May 2010.

\begin{abstract}
Silica matrices doped with calcium and phosphate at various $\mathrm{Ca} / \mathrm{P}$ molar ratios were prepared by the hydrolytic sol-gel methodology. Tetraethylorthosilicate (TEOS) was reacted with calcium ethoxide, in the presence of phosphoric acid as catalyst. Eu III ions were added to the resulting silica, in order to obtain structural information. The samples were dried at $5^{\circ} \mathrm{C}$ and characterized before and after contact with Simulated Body Fluid (SBF). The xerogels were analyzed by thermal analysis (TA), X-ray diffraction (XRD), photoluminescence (PL), and scanning electron microscopy (SEM). The PL spectra revealed Eu III lines characteristic of the ${ }^{5} D_{0} \rightarrow{ }^{7} F_{J}(J=0,1,2,3$, 4) transition of this ion, and they indicated a nonhomogenous distribution of Eu III in the Ca-P-Si matrix. XRD and SEM confirmed the presence of an amorphous and crystalline system before and after contact of the samples with the SBF solution, and the crystalline phases were ascribed to hydroxyapatite and $\beta$-calcium triphosphate. The goal of the work is the preparation of a material can be used as biomaterias at low temperature.
\end{abstract}

Keywords: Luminescence; Biomaterials; Hydroxyapatite

\section{INTRODUCTION}

The bone tissue consists in the combination of a complex material containing an organic matrix (collagen) embedded with inorganic crystals of calcium phosphate (hydroxyapatite $\left.(\mathrm{HA})=\mathrm{Ca}_{10}\left(\mathrm{PO}_{4}\right)_{6}(\mathrm{OH})_{2}\right)$ [1]. $\mathrm{HA}$ is capable of stabilizing the structure of the bone, and it can occur as hydroxyapatite carbonate (HAC), which is present in the human body at $4-7 \%$. HAC is known as biological hydroxyapatite (bio-HA), which also contains a small amount of sodium, potassium, magnesium, fluorite, and chlorate, all of which play an important role in the osteoinductivity of bio-HA [2-5].

HA has been used as bioactive ceramics since the 1970s because of its good biocompatibility; however, its can be easily dissolved in the body fluid. Bioactive glasses are more satisfactory in this sense, since the formation of silica on their surface promotes crystallization of apatite containing calcium and phosphate [6,7]. The formation of hydroxyapatite nanocrystals makes these glasses potentially useful biomaterials, because they promote a favorable environment for osteoconduction, protein adhesion, and osteoblast proliferation [8].

The combination of $\mathrm{HA}$ and $\mathrm{CaCO}_{3}$ with materials such as glasses, inorganic matrices, organic polymers, among others, results in biocompatible materials that facilitate biomineralization [9-13]. The sol-gel process, in turn, is an extremely interesting route for the synthesis of biomaterials due to the presence of hydroxyl groups in the silica matrix $(\mathrm{Si}-\mathrm{OH})$, which promote HA formation $[14,15]$.

In this work, samples containing Si-Ca-P at different $\mathrm{Ca} / \mathrm{P}$ molar ratios were prepared by the sol-gel route, by mixing tetraethylorthosilicate (TEOS), calcium ethoxide, and phosphoric acid. The synthesis consisted in hydrolysis and condensation of the alkoxide, using acid catalysis. Europium chloride was used as structural probe due to its luminescence properties and, because it can replace calcium ion in the phosphate, it furnishes information about the chemical surroundings of Ca II. The resulting xerogel structure, obtained at low temperature, was analyzed by thermal analysis (TG), X-ray diffraction (XRD), photoluminescence (PL), and scanning electron microscopy (SEM), before and after contact with Standard Body Fluid (SBF).

\section{MATERIALS AND METHODS}

\subsection{Sample Preparation}

The reagents were purchase at analytical grade (SigmaAldrich).

The samples were prepared with $\mathrm{Ca} / \mathrm{P}$ molar ratios equal to or different from that encountered in natural hydroxyapatite. The sample denominated $\mathrm{HA}=$ had the same $\mathrm{Ca} / \mathrm{P}$ molar ratio as $\mathrm{HA}$, HA- sample had less $\mathrm{Ca} / \mathrm{P}$ and the $\mathrm{HA}+$ sample had more $\mathrm{Ca} / \mathrm{P}$ than $\mathrm{HA}$. The three samples, $\mathrm{HA}=$, HA + and HA-, were synthesized by the 
sol-gel route. To this end, $9.60 \times 10^{-3}$ mols TEOS, $3.84 \times$ $10^{-3}$ mols calcium ethoxide, and $6.06 \times 10^{-4}(\mathrm{HA}-), 6.73$ $\times 10^{-4}(\mathrm{HA}=)$ or $7.40 \times 10^{-4}(\mathrm{HA}+)$ mols phosphoric acid were added to $16.0 \mathrm{~mL}$ ethanol (solvent), under stirring. The resulting materials were dried at $50^{\circ} \mathrm{C}$ for 1 day. $1 \%$ Europium III chloride was added before gelation, in ethanolic solution, the Eu III ion can replace Ca II ion and used as structural probe.

The samples were obtained the powder form and analyzed by Thermal Analysis (TG), X-Ray Diffraction (XRD), Photoluminescence (PL), and Scanning Electron Microscopy (SEM). They were then immersed in SBF [16], $\mathrm{pH}=7.40$ at $37^{\circ} \mathrm{C}, 0.10 \mathrm{~g}$ of the powder was put in $10 \mathrm{~mL}$ of SBF solution for 19 days. The samples were characterized before and after contact with SBF.

\subsection{Characterizations}

\subsubsection{X-ray Diffraction (XRD)}

The XRD measurements were accomplished at room temperature, with $2 \theta$ values ranging from 4 to $80^{\circ}$ at a resolution of $0.05^{\circ}$, using a Rigaku Geigerflex D/max-c diffractometer employing monochromated $\mathrm{CuK}_{\alpha}$ radiation $(\lambda=1.54 \AA)$.

\subsubsection{Thermal Analysis (TG)}

Thermal analysis (TG) was carried out in a thermal analyzer (TA - Instruments - SDT Q600 - Simultaneous DTA-TG) in nitrogen atmosphere, at a heating rate of $20^{\circ} \mathrm{C} / \mathrm{min}$, from 25 to $1100^{\circ} \mathrm{C}$.

\subsubsection{Photoluminescence (PL)}

Photoluminescence data were obtained under continuous Xe lamp (450W) excitation in a spectrofluometer SPEX - Fluorolog II, at room temperature. The emission was collected at $90^{\circ} \mathrm{C}$ from the excitation beam. The slits were placed at 2.0 and $0.5 \mathrm{~mm}$ for excitation and emission, respectively, giving a band width of 7.0 and $1.0 \mathrm{~nm}$. Oriel 58916 (exc.) and Corning 97612 (em.) filters were employed. Decay curves were measured with a SPEX 1934 phosphorimeter, Xe lamp (5 J/pulse).

\subsubsection{Scanning Electron Microscopy (SEM)}

SEM analysis was performed with a Jeol JSM-T330A microscope, in order to investigate the morphology of the system.

\section{RESULTS AND DISCUSSION}

\subsection{X-ray Diffraction (XRD)}

Figure 1 shows the XRD patterns for the samples prepared with different $\mathrm{Ca} / \mathrm{P}$ molar ratios, before contact with the SBF solution.

The three starting powders present crystalline and amorphous phases, with well-defined diffraction peaks. The crystalline phase displays peaks at $2 \theta=26.5,32.5$, $33.0,49.2$, and 53.1, which can be ascribed to hydroxyapatite (HA), whereas the peaks corresponding to calcium triphosphate (TCP- $\beta$ ) appear at $2 \theta=26.5,30.2$,

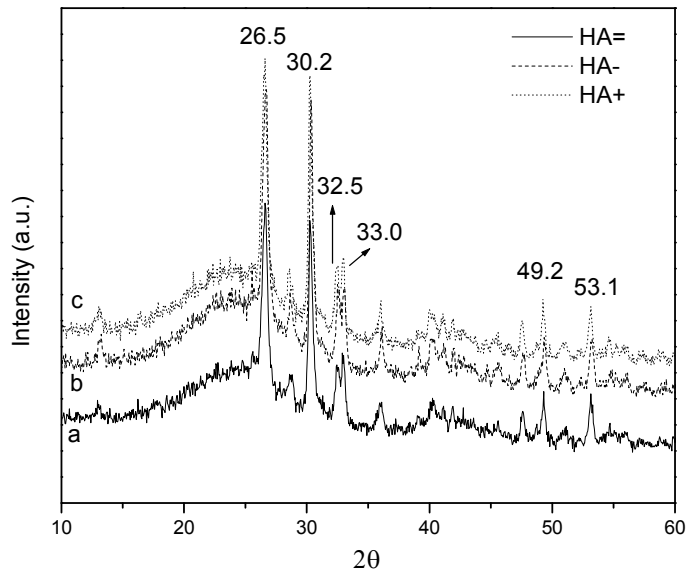

Figure 1. X-ray diffraction vi the samples. (a) HA=; (b) HA-; (c) $\mathrm{HA}+$ before contact with SBF.

and 53.1 [17]. Several other peaks due to other phosphate silicates, such as $\mathrm{Ca}_{5}\left(\mathrm{PO}_{4}\right)_{2} \mathrm{SiO}_{4}$ and $\left(\mathrm{Ca}_{2}\left(\mathrm{SiO}_{4}\right)\right)_{6}$ $\left(\mathrm{Ca}_{3}\left(\mathrm{PO}_{4}\right)_{2}\right)$, can also be observed.

In a previous work, we observed formation of crystalline phases only after sample contact with the SBF solution, but in that case the amount of phosphate in relation to calcium in the material was about $1 \%$ only [13]. The high percentages of phosphate ions $(40 \%)$ in the present samples were crucial to the precipitation of crystalline phosphate nanoparticles in the silica matrix. However, according to literature reports, the double $\mathrm{P}=\mathrm{O}$ bond favors phosphate phase formation in the silica network, thus increasing the tendency toward crystallization [18].

The peak broadening of the XRD reflection can be used to estimate crystallite size in a direction perpendicular to the crystallographic plane, based on the Scherrer equation:

$$
\mathrm{L}=\mathrm{K} \lambda / \beta \cos \theta
$$

where $\mathrm{L}$ denotes the average crystallite size, $\lambda$ represents the wavelength of the X-ray radiation $(\lambda=0.154056 \mathrm{~nm})$, $\mathrm{K}$ is a constant related to crystallite shape and is approximately equal to unity. $\beta$, which is experimentally measured, is the full width of the peak at half of the maximum intensity (rad) and is expressed in its squared form as a squared sum function of the two main contributions, according to Eq.2 depicted below. In the latter equation, $\beta_{1}$ represents the crystallite size contribution to the peak broadening, while $\beta_{2}$ is the instrumental broadening contribution [19].

$$
\beta=\beta_{1}{ }^{2}+\beta_{2}^{2}
$$

On the basis of the XRD data, the average crystallite size was calculated as being approximately $2 \mathrm{~nm}$, indicating the formation of calcium phosphate nanoparticles.

\subsection{Scanning Electronic Microscopy (SEM)}

The morphology of the system was investigated by SEM. Figure 2 depicts the micrographs obtained for the sam- 


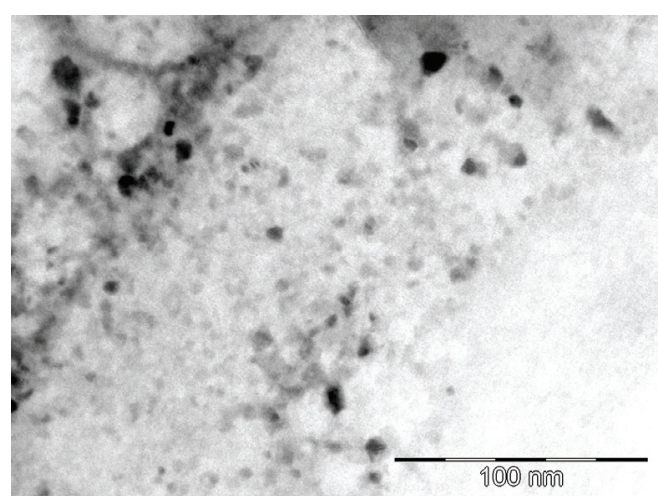

(a)

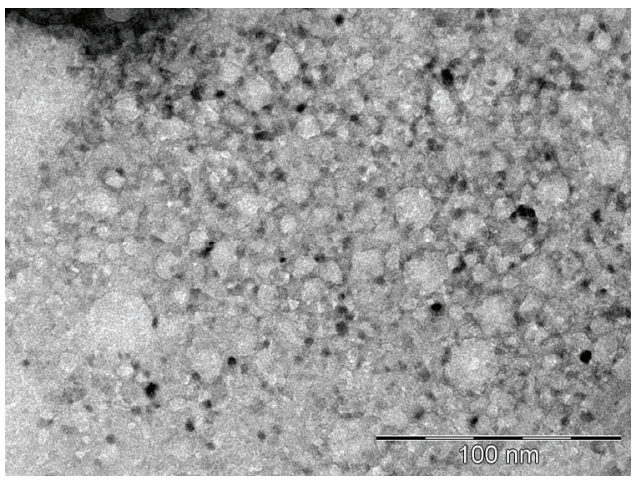

(b)

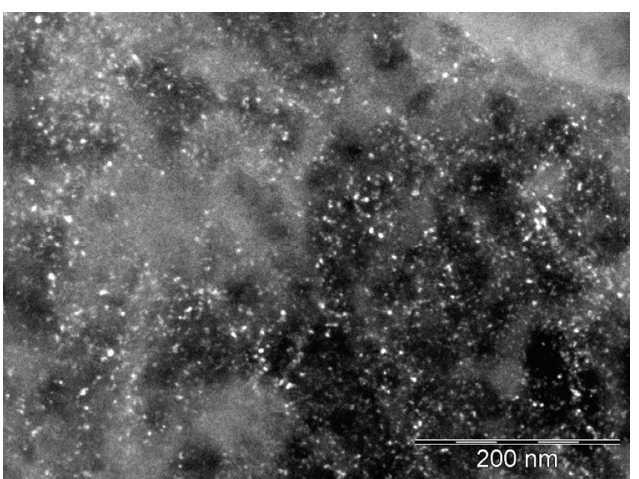

(c)

Figure 2. Micrographs of the samples. (a) HA= white field; (b) HA- white field; (c) HA+ dark field, before contact with SBF.

ples prepared with different $\mathrm{Ca} / \mathrm{P}$ molar ratios, before contact with the SBF solution.

The SEM micrographs reveal the presence of crystalline nanoparticles with an average size of $2 \mathrm{~nm}$, as evidenced by XRD. An amorphous phase is also detected. Crystal particles are also observed by electron diffraction, thus confirming the XRD results.

\subsection{Thermal Analysis (TG/DTG)}

Figures 3(a), (b) and (c) present the thermogravimetric (curve TG) and its derivative (DTG) for the starting samples, before contact with the SBF solution.

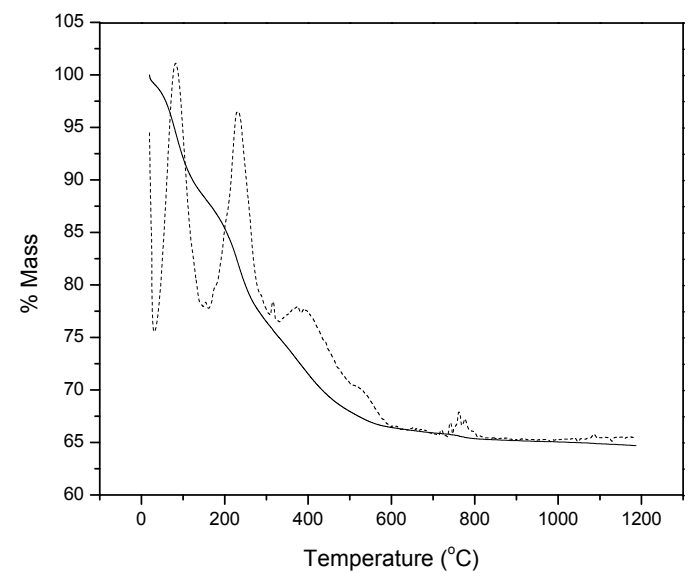

(a)

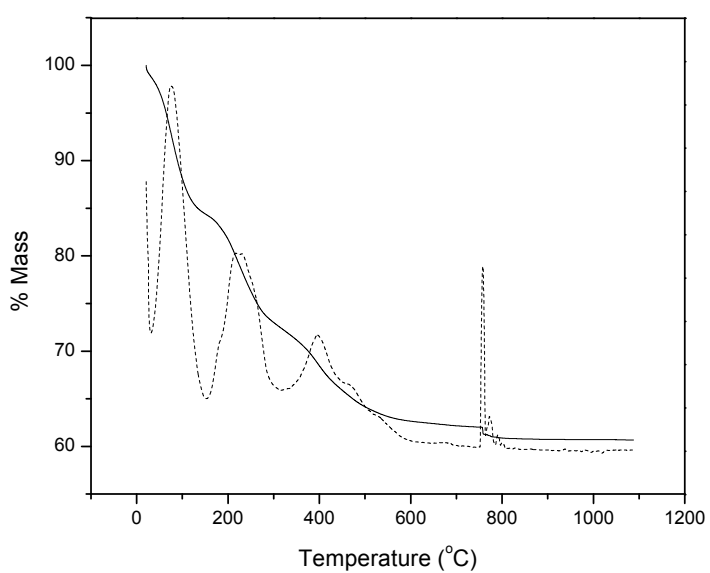

(b)

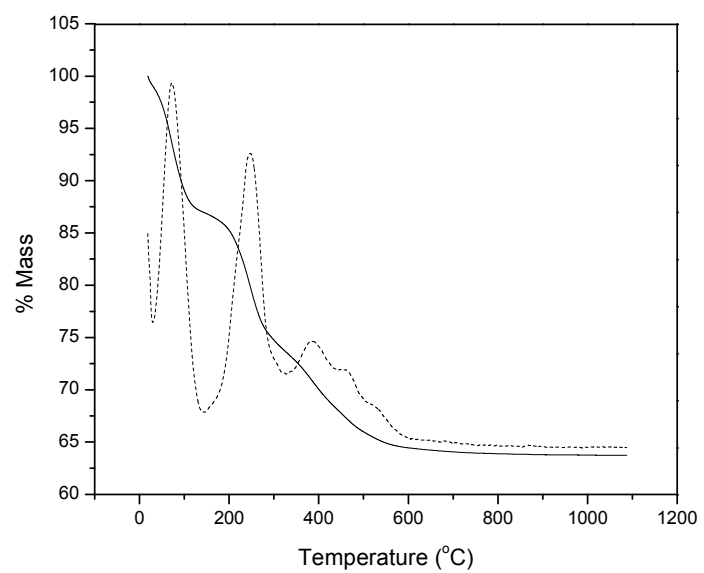

(c)

Figure 3. TG (Solid line) and DTG (Dotted line) curves of the samples. (a) $\mathrm{HA}=$; (b) $\mathrm{HA}-$; (c) $\mathrm{HA}+$ before contact with the SBF solution.

The thermogravimetric curve and its derivative reveal three distinct weight loss stages for all the samples. The first loss occurs at $100^{\circ} \mathrm{C}$ and is ascribed to water and solvent molecules adsorbed on the matrix. The other stages, which took place between 200 and $650^{\circ} \mathrm{C}$, are 
possibly due to the decomposition of residual organic groups of the precursor. The $\mathrm{HA}=$ and $\mathrm{HA}+$ samples have a total weight loss of $35 \%$, while the HA- sample presents a total weight loss of $40 \%$. Nevertheless, the initial weight loss for the samples HA- and HA+ was the same: $15 \%$. The presence of phosphate ion at $\mathrm{Ca} / \mathrm{P}$ molar ratios different from that encountered in natural HA may have contributed to the incomplete polycondensation of the silica matrix. This may have led to a larger quantity of residual $-\mathrm{OH}$ groups on the surface of the matrix and thus a larger number of water molecules adsorbed on the silica surface.

\subsection{Photoluminescence (PL)}

Figures 4 and 5 respectively show the excitation and emission spectra of the samples $\mathrm{HA}=\mathrm{HA}+$, and HAprepared by the sol-gel method, doped with Eu III ions, before contact with the SBF solution. The maximum emission occurs at $590 \mathrm{~nm}\left({ }^{5} \mathrm{D}_{0} \rightarrow{ }^{7} \mathrm{~F}_{1}\right)$, while the maximum excitation takes place at $394 \mathrm{~nm}\left({ }^{5} \mathrm{~L}_{6}\right.$ level). The intensities of the emission bands were normalized.

The emission spectra display transitions arising from ${ }^{5} \mathrm{D}_{0}$ to ${ }^{7} \mathrm{~F}_{\mathrm{J}}(\mathrm{J}=0,1,2,3$, and 4$)$ manifolds. There are three main transitions, namely ${ }^{5} \mathrm{D}_{0} \rightarrow{ }^{7} \mathrm{~F}_{0}$ (around 570 $\mathrm{nm}$ ), ${ }^{5} \mathrm{D}_{0} \rightarrow{ }^{7} \mathrm{~F}_{1}$ (around $595 \mathrm{~nm}$ ), and ${ }^{5} \mathrm{D}_{0} \rightarrow{ }^{7} \mathrm{~F}_{2}$ (around $610 \mathrm{~nm}$ ). The first is a strongly forbidden transition not yet observed with appreciable intensity in some hosts. The ${ }^{5} \mathrm{D}_{0} \rightarrow{ }^{7} \mathrm{~F}_{1}$ transition is forbidden as electric dipole, but allowed as magnetic dipole. This is the only transition that takes place when Eu III occupies a site coinciding with a symmetry centre. When the Eu III ion is situated at a site lacking an inversion centre, the transition corresponding to even $\mathbf{J}$ values (except 0 ) are electric dipole allowed, and red emission can be observed. The ${ }^{5} \mathrm{D}_{0} \rightarrow{ }^{7} \mathrm{~F}_{1}$ transition can also be observed as a magnetic dipole allowed transition. Further on, all the lines corresponding to this transition split into a number

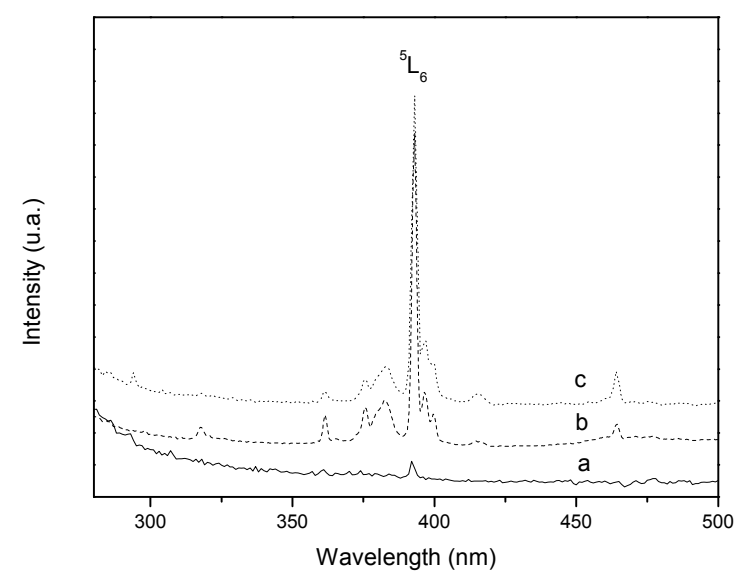

Figure 4. Excitation spectra of the samples. (a) HA=; (b) HA-; (c) HA+ doped with Eu III ions before contact with the SBF solution, $\lambda_{\mathrm{em}}=590 \mathrm{~nm}$.

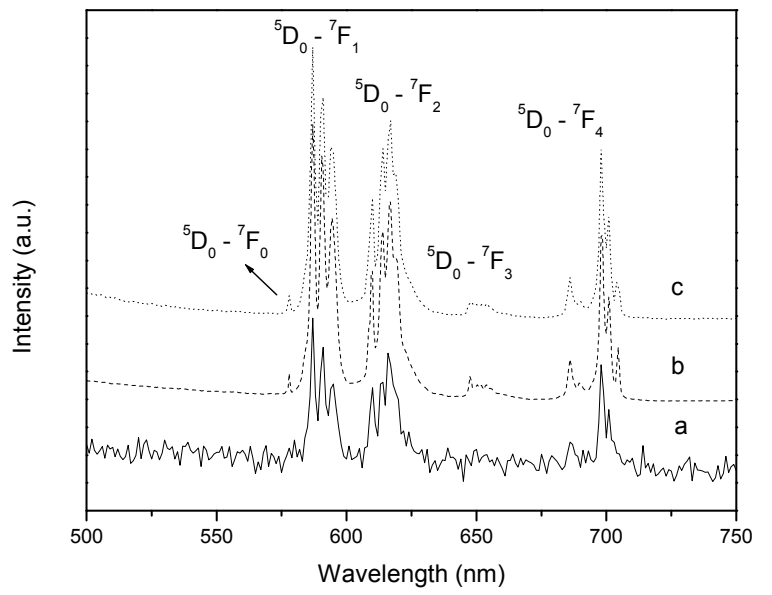

Figures 5. Emission spectra of the samples. (a) HA=; (b) HA-; (c) $\mathrm{HA}+$ doped with Eu III ions before contact with the SBF solution, $\lambda_{\text {exc. }}=394 \mathrm{~nm}$.

of components depending on the local symmetry [20].

When Eu III is located at a low symmetry site (without an inversion center), the ${ }^{5} \mathrm{D}_{0} \rightarrow{ }^{7} \mathrm{~F}_{2}$ emission transition often predominates in the emission spectrum, so the Eu III ions occupy a non-inversion symmetric site [21]. The ${ }^{5} \mathrm{D}_{0} \rightarrow{ }^{7} \mathrm{~F}_{0}$ transition of Eu III is only allowed in the case of Cs, Cn and Cnv symmetries of the Eu III sites in the crystalline state [22]. The hexagonal unit-cell HA contains ten cations distributed between two crystallographic sites: four on type (1) sites and six on type (2) sites. $\mathrm{Ca}$ (1) ions present $\mathrm{C}_{3}$ symmetry and are surrounded by nine oxygen atoms. $\mathrm{Ca}(2)$ ions present $\mathrm{Cs}$ symmetry and are surrounded by six oxygen atoms [2325]. There are literature reports stating that $\mathrm{Ca}(1)$ and $\mathrm{Ca}(2)$ ions $(\mathrm{r}=0.99 \AA$ \&́) can be replaced with $\mathrm{Pb}$ II $(\mathrm{r}=$

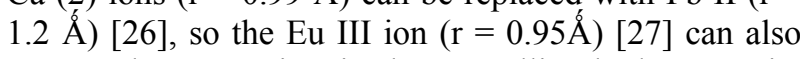
occupy the Ca II sites in the crystalline hydroxyapatite and $\beta$-TCP, as well as in amorphous silica. The emission spectra of $\mathrm{Eu}^{3+}$ is not similar in glasses hosts, as discussed in literature [28-30].

The Eu III emission bands in the spectra of Figure 5 reveal a nonhomogenous distribution of the ion in the Si-Ca-P matrix [31-33].

Because of its electrical-dipole nature [34], the relative intensity of the ${ }^{5} \mathrm{D}_{0} \rightarrow{ }^{7} \mathrm{~F}_{0}$ and ${ }^{5} \mathrm{D}_{0} \rightarrow{ }^{7} \mathrm{~F}_{2}$ transitions is strongly dependent on the Eu III surroundings. In contrast, the band corresponding to the ${ }^{5} \mathrm{D}_{0} \rightarrow{ }^{7} \mathrm{~F}_{1}$ transition has a magnetic-dipolar nature whose intensity is unaffected by the ion's surroundings. Therefore, the latter transition can be considered a standard to measure the relative intensity of the other bands $[35,36]$, and the ${ }^{5} \mathrm{D}_{0}$ $\rightarrow{ }^{7} \mathrm{~F}_{2}$ emission intensity can thus provide valuable information about environmental changes around the $\mathrm{Eu}$ III ions. Table 1 shows the intensity of the ${ }^{5} \mathrm{D}_{0} \rightarrow{ }^{7} \mathrm{~F}_{0}$ and ${ }^{5} \mathrm{D}_{0} \rightarrow{ }^{7} \mathrm{~F}_{2}$ transitions relative to the ${ }^{5} \mathrm{D}_{0} \rightarrow{ }^{7} \mathrm{~F}_{1}$ transition. 
Table 1. Relative intensity of the ${ }^{5} \mathrm{D}_{0} \rightarrow{ }^{7} \mathrm{~F}_{0}$ and ${ }^{5} \mathrm{D}_{0} \rightarrow{ }^{7} \mathrm{~F}_{2}$ transitions with respect to the ${ }^{5} \mathrm{D}_{0} \rightarrow{ }^{7} \mathrm{~F}_{1}$ transition in the emission spectra of the samples HA=, HA+ and HA- doped with Eu III, before contact with SBF.

\begin{tabular}{ccc}
\hline Samples & ${ }^{5} \mathrm{D}_{0} \rightarrow{ }^{7} \mathrm{~F}_{0} / \mathrm{D}_{0} \rightarrow$ & ${ }^{5} \mathrm{D}_{0} \rightarrow{ }^{7} \mathrm{~F}_{2} / \mathrm{D}_{0} \rightarrow$ \\
\hline $\mathrm{HA}=$ & 0.09 & 1.13 \\
$\mathrm{HA}-$ & 0.09 & 1.06 \\
$\mathrm{HA}+$ & 0.11 & 1.11 \\
\hline
\end{tabular}

The similar relative intensities of the transitions indicate that the environment around the Eu III ion is similar in the three samples, and the ion can be located either in the silica matrix or in calcium phosphate.

The characterized samples were then placed in SBF solution for 19 days, followed by characterization using the same techniques mentioned above.

\subsection{XRD and TEM}

Figure 6 depicts the XRD patterns for the samples prepared with different $\mathrm{Ca} / \mathrm{P}$ molar ratios, after contact with the SBF solution.

The XRD patterns depicted in Figure 6 display the same peaks observed for the samples not submitted to contact with SBF solution. Therefore, the crystalline phase formed during the sol-gel process remains intact in the silica matrix after sample immersion into SBF. TEM analysis also reveals that the crystalline phase does not disappear after contact with the SBF solution, and the presence of calcium phosphate nanoparticles in the samples is confirmed by this technique. Furthermore, the Sherrer formula corroborates the average size of the crystalline particles, which is $2 \mathrm{~nm}$.

\subsection{Thermal Analysis}

Figures 7(a), (b) and (c) present the thermogravimetric curve (TG) and its derivative (DTG) for the three samples,

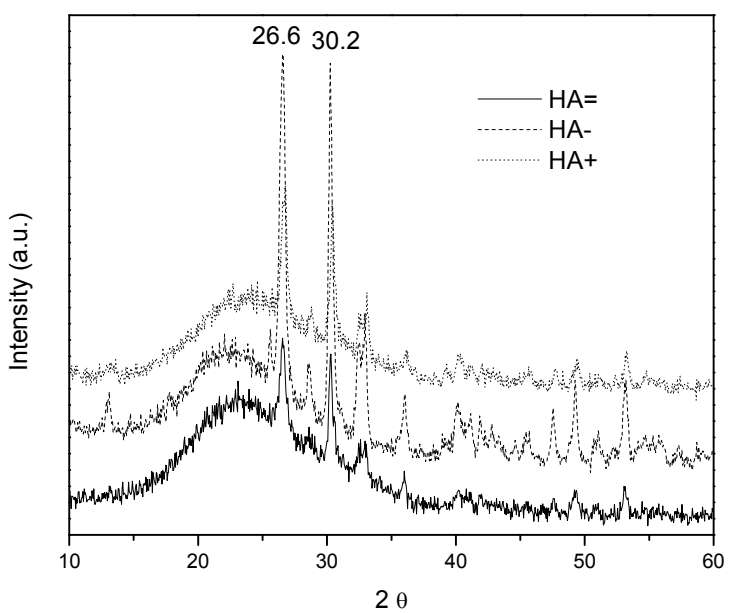

Figure 6. X-ray diffraction of the samples. (a) HA=; (b) HA-; (c) $\mathrm{HA}+$, after contact with $\mathrm{SBF}$.

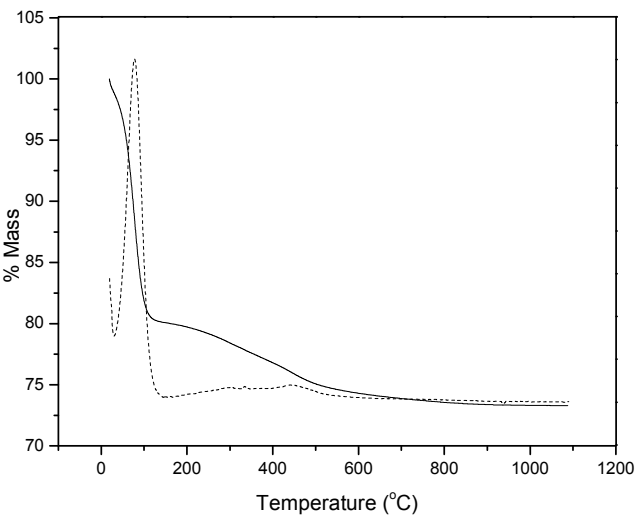

(a)

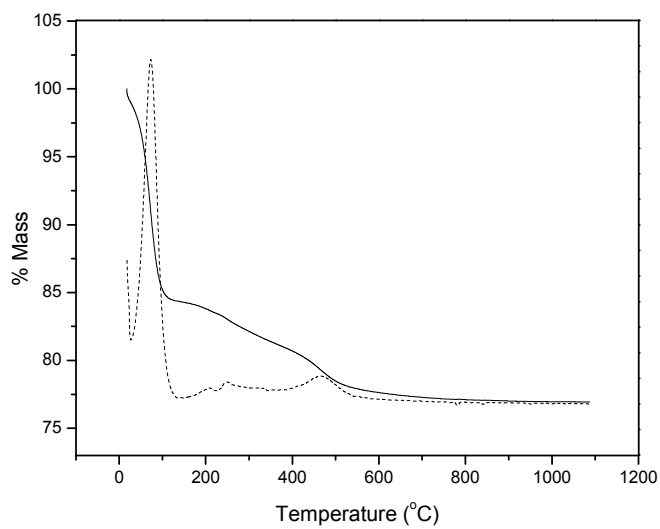

(b)

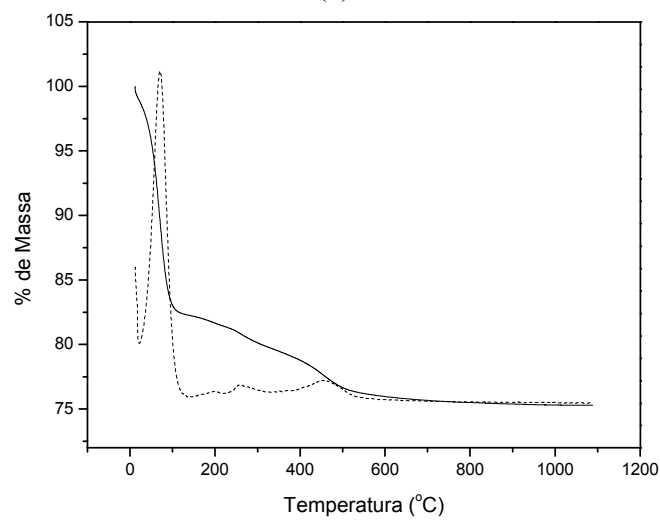

(c)

Figures 7. TG (Solid line) and DTG (Dotted line) curves of the samples. (a) $\mathrm{HA}=$; (b) $\mathrm{HA}-$; (c) $\mathrm{HA}+$ after contact with the SBF solution.

after contact with the SBF solution.

The thermogravimetric curve and its derivative give evidence of two weight losses for all the samples. The main loss occurs at about $100^{\circ} \mathrm{C}$, ascribed to water molecules and solvent. As for the second weight loss stage, it took place between 200 and $650^{\circ} \mathrm{C}$ before the samples were immersed into SBF and the weight loss percentage was $20 \%$. After contact with the SBF solution, this weight loss percentage reduced to $7 \%$ in the same temperature range. An exchange between the solid 
sample and the SBF solution probably occurred, with residual product being removed from the silica matrix after contact.

\subsection{Photoluminescence (PL)}

Figures 8 and 9 respectively show the excitation and emission spectra of the samples $\mathrm{HA}=$, HA+, and HAprepared by the sol-gel method, doped with Eu III ions, after contact with the SBF solution. The maximum emission occurs at $590 \mathrm{~nm}\left({ }^{5} \mathrm{D}_{0} \rightarrow{ }^{7} \mathrm{~F}_{1}\right)$, while the maximum excitation takes place at $394 \mathrm{~nm}\left({ }^{5} \mathrm{~L}_{6}\right.$ level). The intensities of the emission bands were normalized.

The emission spectra display transitions arising from ${ }^{5} \mathrm{D}_{0}$ to ${ }^{7} \mathrm{~F}_{\mathrm{J}}(\mathrm{J}=0,1,2,3$, and 4$)$ manifolds. The Eu III emission bands in the spectra of Figure 9 are characteristic of a nonhomogenous distribution of this ion in the $\mathrm{Si}-\mathrm{Ca}$-P matrix, as observed for the samples before contact with the SBF solution.

The relative intensity of the ${ }^{5} \mathrm{D}_{0} \rightarrow{ }^{7} \mathrm{~F}_{0}$ and ${ }^{5} \mathrm{D}_{0} \rightarrow{ }^{7} \mathrm{~F}_{2}$

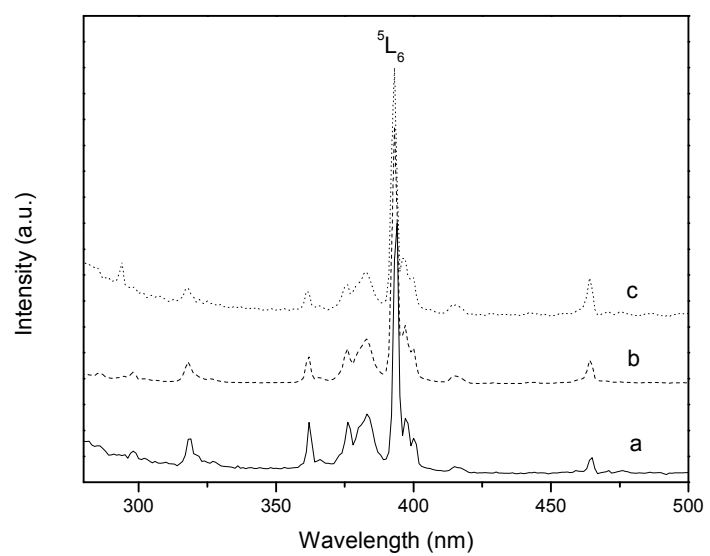

Figures 8. Excitation spectra of the samples. (a) HA=; (b) HA-; (c) HA+ doped with Eu III ions after contact with SBF solution, $\lambda_{\text {em. }}=590 \mathrm{~nm}$.

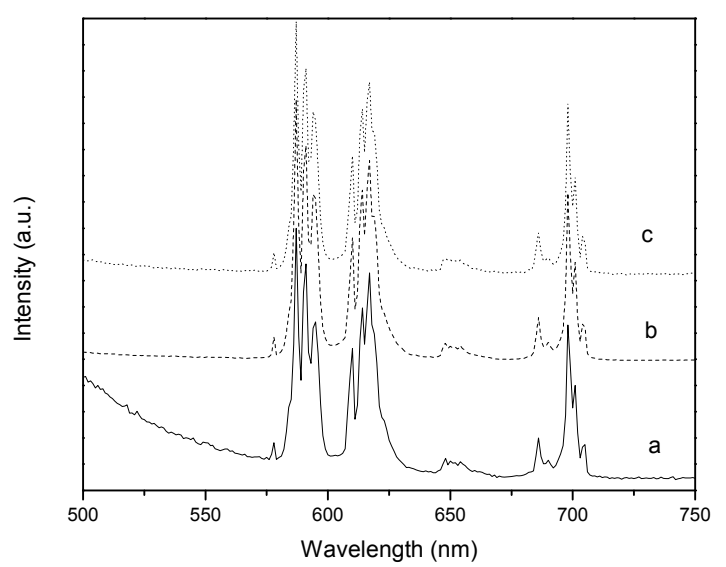

Figure 9. Emission spectra of the samples. (a) HA=; (b) HA-; (c) HA+ doped with Eu III ions after contact with the SBF solution, $\lambda_{\text {exc. }}=394 \mathrm{~nm}$.
Table 2. Relative intensity of the ${ }^{5} \mathrm{D}_{0} \rightarrow{ }^{7} \mathrm{~F}_{0}$ and ${ }^{5} \mathrm{D}_{0} \rightarrow{ }^{7} \mathrm{~F}_{2}$ transitions with respect to the ${ }^{5} \mathrm{D}_{0} \rightarrow{ }^{7} \mathrm{~F}_{1}$ transition in the emission spectra of the samples $\mathrm{HA}=, \mathrm{HA}+$ and HA- doped with Eu III, after contact with SBF.

\begin{tabular}{ccc}
\hline Samples & ${ }^{5} \mathrm{D}_{0} \rightarrow{ }^{7} \mathrm{~F}_{0}{ }^{5} \mathrm{D}_{0} \rightarrow$ & ${ }^{5} \mathrm{D}_{0} \rightarrow{ }^{7} \mathrm{~F}_{2} /{ }^{5} \mathrm{D}_{0} \rightarrow$ \\
\hline $\mathrm{HA}=$ & 0.05 & 0.99 \\
$\mathrm{HA}-$ & 0.09 & 1.11 \\
$\mathrm{HA}+$ & 0.12 & 1.15 \\
\hline
\end{tabular}

transitions was obtained by measuring the area under the emission band. Table 2 shows the intensity of the ${ }^{5} \mathrm{D}_{0} \rightarrow$ ${ }^{7} \mathrm{~F}_{0}$ and ${ }^{5} \mathrm{D}_{0} \rightarrow{ }^{7} \mathrm{~F}_{2}$ transitions relative to the ${ }^{5} \mathrm{D}_{0} \rightarrow{ }^{7} \mathrm{~F}_{1}$ transition.

There were only slight changes in the relative intensity of the emission bands, indicating that the environment around the Eu III ion is not affected upon contact of the samples with the SBF solution. This is because $\mathrm{Eu}$ III probably occupies a stable site in the matrix and in the phosphate nanoparticles. The change in the relative intensity of the ${ }^{5} \mathrm{D}_{0} \rightarrow{ }^{7} \mathrm{~F}_{0}$ and ${ }^{5} \mathrm{D}_{0} \rightarrow{ }^{7} \mathrm{~F}_{2}$ transitions was more significant for the sample $\mathrm{HA}=$, which can be ascribed to possible dissolution of the matrix and phosphate into the SBF solution, as discussed in the literature [18].

\section{CONCLUSIONS}

The concentration of phosphate ions is crucial to the formation of crystalline calcium phosphate in the silica matrix, when compared with results from a previous work. The formation of nanocrystals is very important for the future application of these solids as biomaterials.

The Eu III ion can occupy different sites in these materials; that is, it can replace the calcium ion in the phosphate or in the matrix.

Thermal analysis revealed that residues from the synthesis can be removed after washing with water, but this does not affect nanocrystal formation.

The period during which the materials remain in contact with the SBF solution is not sufficient to promote their reaction with the solution. Literature reports mention that biomaterials need to be placed in SBF for a certain contact time before calcium phosphate starts to precipitate, but this process depends on sample composition. In our case, the sample $\mathrm{HA}=$, which contains the same $\mathrm{Ca} / \mathrm{P}$ molar ratio as natural $\mathrm{HA}$, seems to undergo dissolution after a certain contact time with SBF, and we think that a longer contact time could lead to reprecipitation of the HA.

\section{ACKNOWLEDGEMENTS}

The authors acknowledge FAPESP, CNPq and CAPES (Brazilian 
research funding agencies) for their financial support of this work.

\section{REFERENCES}

[1] Jaeger, C., Groom, N.S., Bowe, E.A., Horner, A., Davies, M.E., Murray, R.C. and Duer, M.J. (2005) Investigation of the nature of the protein-mineral interface in bone by solid-state NMR. Chemistry of Materials, 17(12), 30593061.

[2] Kawachi, E.Y., Bertran, C.A., Reis, R.R. dos and Alves, O.L. (2000) Biocerâmicas: tendências e perspectivas de uma área interdisciplinar. Química Nova, 23(4), 518-522.

[3] Jillavenkatesa, A. and Condrate SR, R.A. (1998) Sol-gel processing of hydroxyapatite. Journal of Materials Science, 33(16), 4111-4119.

[4] Pietak, A.M. and Sayer, M. (2006) Functional atomic force microscopy investigation of osteopontin affinity for silicon stabilized tricalcium phosphate bioceramic surfaces. Biomaterials, 27(1), 3-14.

[5] Cho, S., Nakanishi, K., Kokubo, T., Soga, N., Ohtsuki, C. and Nakamura, T. (1996) Apatite formation on silica gel in simulated body fluid: Its dependence on structures of silica gels prepared in different media. Journal of Biomedical Materials Research Part B: Applied Biomaterials, 33(3), 145-151.

[6] Cheng, K., Zhang, S. and Weng, W. (2006) Sol-gel preparation of fluoridated hydroxyapatite in $\mathrm{Ca}\left(\mathrm{NO}_{3}\right)_{2}-$ $\mathrm{PO}(\mathrm{OH})_{3-\mathrm{x}}(\mathrm{OEt})_{\mathrm{x}}-\mathrm{HPF}_{6}$ system. Journal of Sol-Gel Science and Technology, 38(1), 13-17.

[7] Arcos, E., Pena, J. and Vallet-Regí, M., (2003) Influence of a $\mathrm{SiO}_{2}-\mathrm{CaO}-\mathrm{P}_{2} \mathrm{O}_{5}$ sol-gel glass on the bioactivity and controlled release of ceramic/polymer/antibiotic mixed materials. Chemistry of Materials, 15(21), 4132-4138.

[8] Lee, H.J., Choi, H.W., Kim, K.J. and Lee, S.C. (2006) Modification of hydroxyapatite nanosurfaces for enhanced colloidal stability and improved interfacial adhesion in nanocomposites. Chemistry of Materials, 18(21), 51115118.

[9] Andrade, A.L. and Domingues, R. (2006) Cerâmicas bioativas: estado da arte. Química Nova, 29(1), 100-104.

[10] Rámila, A., Padilla, P., Muñoz, B. and Vallet-Regí, M. (2002) A new hydroxyapatite/glass biphasic material: In vitro bioactivity. Chemistry of Materials, 14(6), 24392443.

[11] Doğan, Ö. and Öner, M. (2006) Biomimetic mineralization of hydroxyapatite crystals on the copolymers of vinylphosphonic acid and 4-vinilyimidazole. Langmuir, 22 (23), 9671-9675.

[12] Iwatsubo, T., Sumaru, K., Kanamori, T., Shinbo, T. and Yamaguchi, T. (2006) Construction of a new artificial biomineralization system. Biomacromolecules, 7(1), 95100.

[13] Bandeira, L.C., Avila, L.R., Cestari, A., Calefi, P.S., Ciuffi, K.J., Nassar, E.J., Salvado, I.M. and Fernandes, M.H.F.V. (2010) Cerâmica submitted.

[14] Vallet-Regí, M. and Rámila, A. (2000) New bioactive glass and changes in porosity during the growth of a carbonate hydroxyapatite layer on glass surfaces. Chemistry of Materials, 12(4), 961-965.

[15] Hench, L.L. (1998) Sol-gel silica: Properties, processing and technology transfer. Noyes Publications, Bracknell.
[16] Kokubo, T. (1991) Bioactive glass ceramics: Properties and applications. Biomaterials, 12(1), 155-163.

[17] Park, E., Condrate, R.A., Lee, D., Kociba, J. and Gallagher, P.K. (2002) Journal of Material Science: Materials in Medicine, 13, 211.

[18] Petil, O., Zanotto, E.D. and Hench, L.L. (2001) Highly bioactive $\mathrm{P}_{2} \mathrm{O}_{5}-\mathrm{Na}_{2} \mathrm{O}-\mathrm{CaO}-\mathrm{SiO}_{2}$ glass-ceramics. Journal of Non-Crystalline Solids, 292(1-3), 115-126.

[19] Li, J., Chem, Y., Yin, Y., Yao, F. and Yao, K. (2007) Modulation of nano-hydroxyapatite size via formation on chitosan-gelatin network film in situ. Biomaterials, 28(5), 781-790.

[20] Kake, M.A., Joshi, C.P., Moharil, S.V., Muthal, P.L. and Dhopte, S.M. (2008) Luminescence in $\mathrm{LaCaAl}_{3} \mathrm{O}_{7}$ prepared by combustion synthesis. Journal of Luminescence, 128(7), 1225-1228.

[21] Ravichandran, D., Roy, R., Chaklowskoi, A.G., Hunt, C.E., White, W.B. and Erdei, S. (1997) Fabrication of $\mathrm{Y}_{3} \mathrm{Al}_{5} \mathrm{O}_{12}: \mathrm{Eu}$ thin films and powders for field emission display applications. Journal of Luminescence, 71(4), 291-297.

[22] Bao, A., Tao, C. and Yong, H. (2007) Synthesis and luminescent properties of nanoparticles $\mathrm{GdCaAl}_{3} \mathrm{O}_{7}: \mathrm{RE}^{3+}$ $(\mathrm{RE}=\mathrm{Eu}, \mathrm{Tb})$ via the sol-gel method. Journal of Luminescence, 126(2), 859-865.

[23] Ternane, R., Trabelsi-Ayedi, M., Kbir-Ariguib, N. and Piriou, B. (1999) Luminescent properties of $\mathrm{Eu}^{3+}$ in calcium hydroxyapatite. Journal of Luminescence, 81(3), 165-170.

[24] Jagannathan, R. and Kottaisamy, M. (1995) $\mathrm{Eu}^{3+}$ luminescence: A spectral probe in $\mathrm{M}_{5}\left(\mathrm{PO}_{4}\right)_{3} \mathrm{X}$ apatites $(\mathrm{M}=\mathrm{Ca}$ or $\mathrm{Sr} ; \mathrm{X}=\mathrm{F}^{-}, \mathrm{Cl}^{-}, \mathrm{Br}^{-}$or $\left.\mathrm{OH}^{-}\right)$. Journal of Physics: Condensed Matter, 7(44), 8453-8466.

[25] Piriou, B., Fahmi, D., Dexpert-Ghys, J., Taitai, A. and Lacout, J.L. (1987) Unusual fluorescent properties of $\mathrm{Eu}^{3+}$ in oxyapatites. Journal of Luminescence, 39(2), 97-103.

[26] Mehanaoui, M., Panczer, G., Ternane, R., Trabelsi-Ayedi, M. and Boulon, G. (2008) Structural and spectroscopic characterizations in $\mathrm{Pb}^{2+}$-doped calcium hydroxyapatites. Optical Materials, 30(11), 1672-1676.

[27] Yang, Y., Ren, Z., Tao, Y., Cui, Y. and Yang, H. (2009) $\mathrm{Eu}^{3+}$ emission in $\mathrm{SrAl}_{2} \mathrm{~B}_{2} \mathrm{O}_{7}$ based phosphors. Current Applied Physics, 9(3), 618-621.

[28] Lin, H., Yang, D., Liu, G., Ma, T., Zhai, B., An, Q., Yu, J., Wang, X., Liu, X. and Pun, E.Y.-B. (2005) Optical absorption and photoluminescence in $\mathrm{Sm}^{3+}$ - and $\mathrm{Eu}^{3+}$ doped rare-earth borate glasses. Journal of Luminescence, 113(1-2), 121-128.

[29] Krebs, J.K. and Brownstein, J.M. (2007) Site-selective spectroscopy of $\mathrm{Eu}^{3+}$ in bioactive glass. Journal of $\mathrm{Lu}$ minescence, 124(2), 257-259.

[30] Krebs, J.K., Brownstein, J.M. and Gibides, J.T. (2008) Decay dynamics of europium excited states in bioactive glasses. Journal of Luminescence, 128(5-6), 780-782.

[31] Hazenkamp, M.F., Van der Veen, A.M.H., Feiken, W. and Blasse, G. (1992) Hydrated rare-earth-metal ion-exchanged zeolite a: Characterization by luminescence spectroscopy. Part 2-The $\mathrm{Eu}^{3+}$ ion. Journal of the Chemical Society, Faraday Transactions, 88(1), 141-144.

[32] Rice, D.K., Deshaser, L.G. (1969) Spectral broadening of europium ions in glass. Physics Review B, 186(2), 387- 
392.

[33] Reisfeld, R. (1984) Fluorescence and non-radiative relaxations of rare earths in amorphous media and on high surface area supports: A review. Journal of the Electrochemical Society, 131(6), 1360-1364.

[34] Blasse, G. (1990) Interaction between optical centers and their surroundings: An inorganic chemist's approach.
Advances in Inorganic Chemistry, 35, 319-402.

[35] Richardson, F.S. (1982) Terbium(III) and Europium(III) ions as luminescent probes and stains for biomolecular systems. Chemical Reviews, 82, 541-552.

[36] Reisfeld, R. (1973) Spectra and energy transfer of rare earths in inorganic glasses. Structure and Bonding, 13, 53-98. 